\title{
American Voters Do Punish Overt Undemocratic Behavior at the Polls: Natural Experimental Evidence from the 2021 Insurrection of the U.S. Capitol
}

\author{
Sam van Noort* \\ First version: September 10, 2021 \\ This version: November 1, 2021
}

\begin{abstract}
Existing research suggests that overt undemocratic behavior by elected officials is insufficiently punished by American voters to electorally discourage democratic backsliding. Evidence for this proposition comes primarily from hypothetical survey experiments with relatively weak treatments. I test this hypothesis using a natural experiment with a powerful treatment: Donald Trump's incitement of the insurrection of the U.S. Capitol on January 6, 2021. The insurrection was unexpected to the general public, did not coincide with other events that could plausibly affect public opinion, and occurred while Gallup was conducting a nationally representative survey using random digit dialing. Comparing vote choice intention among respondents that were interviewed just before, and just after, the insurrection occurred suggests that the insurrection caused a $10.8 \%$ decline in support for the Republican Party, and an $8.4 \%$ increase in support for the Democratic Party. Politicians interested in winning elections have strong incentives to avoid insurrection-like events from occurring.
\end{abstract}

Keywords: Democratic Backsliding, Accountability, Voter Behavior Words: 3,993 (excl. online appendix and abstract)

${ }^{*} \mathrm{PhD}$ Candidate at the University of Cambridge and Fellow at the Niehaus Center for Globalization and Governance of Princeton University. I would like to thank Andy Eggers, Alex Gazmararian, Tanushree Goyal, Roza Khoban, Daniel Lyng, Dawn Teele, Duy Trinh, Milan Svolik, James Vreeland, and seminar participants at APSA 2021 for helpful comments and suggestions. I thank Jeremy Darrington, Bobray Bordelon, and Kris Hodgins for providing access to the Gallup data. This study was pre-registered at the EGAP registry. 


\section{Introduction}

Politicians that cannot win through free and fair elections self-evidently have an incentive to rig the electoral system for political gain. While democratic norms among politicians could in principle self-constrain politicians from doing so, this mechanism, even if such norms exist, becomes more and more brittle ones the stakes of elections increases. For democracy to be truly self-enforcing it is therefore necessary that politicians anticipate that, were they to behave undemocratically, their own supporters would punish them by voting for a competitor in sufficiently large numbers to bring about their defeat (Graham and Svolik, 2020; Svolik, 2020 ).

It is extremely disconcerting therefore that a number of recent studies find that the American electorate may no longer provide this shield of protection again democratic backsliding ${ }^{1}$ Graham and Svolik (2020) find that in regular state legislative elections between a Democrat and a Republican, and where the candidates differ substantively on economic and social policy (i.e., virtually every election in the United States), a mere $3.5 \%$ of the electorate is willing to punish clear undemocratic behavior by politicians if this means that they are forced to vote for a politician that is further away from their own policy preferences..$^{2}$ McCoy, Simonovits and Littvay (2020) and Albertus and Grossman (2021) meanwhile find that Americans are remarkably hypocritical when it comes to democratic backsliding, supporting the same anti-democratic state executive behavior when their own party is in power, while

${ }^{1}$ This concern is of course hardly limited to the United States alone. Indeed, a rapidly growing literature exists on the issue of democratic backsliding in general (e.g., Bermeo (2016), Cleary and Öztürk (2020), Grillo and Prato (Forthcoming), Haggard and Kaufman (2021), Lührmann (2021), and Waldner and Lust (2018)) and on the role of voters in tolerating democratic backsliding in particular (e.g., Cho and Hwang (2021), Magaloni (2006), and Svolik $(2019,2020))$.

2 Carey et al. $(\overline{2020})$ do find that American voters sufficiently punish undemocratic behavior when they are not forced to give up any of their own policy preferences. 
condemning it if the opposing party is in power.

This important existing evidence not withstanding significant uncertainty remains as to whether American voters do indeed not punish undemocratic behavior by elected officials sufficiently strongly to reasonably influence elections. First, all existing evidence is survey experimental in nature. It remains unclear therefore whether voters would not sufficiently

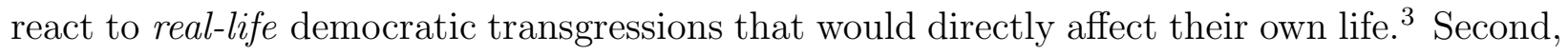
all existing studies employ important but nevertheless not truly fundamental and decisive forms of democratic backsliding (e.g., whether a candidate supported a proposal to reduce the number of polling places in areas that largely support the opposing party). It is unclear therefore whether American voters will not be an effective electoral check to more extreme forms of democratic backsliding that would truly change the rules of the game (e.g., a state executive refusing to leave office after losing an election).

To address these issues I analyze the results of a novel natural experiment that occurred because Donald Trump's incitement of the insurrection of the U.S. Capitol on January 6, 2021, unexpectedly occurred while Gallup was conducting a nationally representative public opinion survey among 1,023 adult Americans. Given that Gallup samples respondents using random digit dialing the probability of any particular individual to be interviewed before or after the insurrection is plausibly exogenous to any pre-treatment characteristics that may otherwise affect vote choice. Furthermore, given that there were arguably no other events surrounding January 6, 2021 that could plausibly explain major changes in political party alliance I can recover the average treatment effect of inciting the insurrection by simply comparing support for the Republican Party among respondents that happened to

${ }^{3}$ Graham and Svolik (2020) are an exception to this. They also analyze the causal effect of Republican Greg Gianforte hitting a journalist in the face (which they define as antidemocratic behavior) during Montana's 2017 special election for the U.S. House of Representatives. This paper differs from Graham and Svolik (2020) by focusing on a more extreme form of undemocratic behavior that had a more structural effect on American democracy. 
be interviewed just before, and just after, the insurrection occurred.

Using this natural experiment I find that Americans do in fact punish behavior as extreme as inciting an insurrection strongly enough to decisively influence presidential elections. More specifically, I find that electoral support for the Republican Party went down 10.8\% as a result of Donald Trump's incitement of the insurrection. Crucially, the majority of voters switched to supporting the Democratic Party, rather than becoming independents, causing the expected vote share of the Democratic Party to simultaneously increase by $8.4 \%$. Voters in swing states imposed similar levels of electoral punishment as voters in non-swing states, suggesting that this event had the capacity to strongly shift U.S. presidential election results.

These results suggest that voters may be a more viable constrain on democratic backsliding than the existing literature presumes. This is even the case in the United States, where the electorate is particularly strongly polarized, and where the cost of internalizing democratic backsliding concerns is therefore particularly costly for voters (Svolik, 2020). This finding is in line with survey data that suggests that in many democratic backsliding countries the majority of voters actually tends to be relatively liberal and pro-democracy. Democratic backsliding nonetheless occurs in such settings because antidemocratic incumbents are able to leverage the electoral system to rule as a (super)majority even while winning only a minority of the votes. This applies not only to the United States, where Donald Trump was elected with almost 3 million less votes than Hillary Clinton, but also to other backsliding countries such as Hungary, Poland, Serbia, Turkey, Russia, North Macedonia, Venezuela, and Zambia (Haggard and Kaufman, 2021). In sum, the fight against democratic backsliding is perhaps as much about letting the voice of the majority be heard, as it is about getting the majority to value democracy more.

The paper also contributes to the ongoing study of the consequences of the January 6 insurrection, which is likely to prove one of the major watershed moments in $21^{\text {th }}$ century American political history. My results contrast relatively sharply with existing reports, which have tended to emphasized how radically different self-identifying Republicans and 
Democrats have perceived the events of January 6, 2021. A post-January 6 YouGov (2021) poll, for example, found that approximately $45 \%$ of self-identifying Republicans actually supported the storming of the Capitol, that $52 \%$ of Republicans blamed Joe Biden rather than Donald Trump for inciting the unrest, and that only $27 \%$ of self-identified Republicans saw the insurrection as a threat to democracy. My results do not dispute these reports. Instead, my results show that there was a major shift in the number of people self-identifying as Republican and Democrat as a result of the insurrection. Within the now much smaller remaining group of Republican-leaning voters it could well be true that many trivialized or straight-out denied the nature and gravity of the events that occurred on January 6, 2021.

\section{The insurrection of the U.S. Capitol}

On November 3, 2020 Joe Biden (Democrat) won the U.S. presidential election of sitting U.S. president Donald Trump (Republican) with a little more than 7 million popular votes (and 74 Electoral College votes) difference. Despite this enormous difference in the number of votes, and the absence of any evidence of widespread voting fraud, Donald Trump claimed that the election was fraudulent and that he was the true winner of the election.

After several months of constant misinformation regarding the election, and a wide range of highly publicized court cases (which were all essentially dismissed for a lack of evidence), Donald Trump held a speech at the "Stop the Steal" rally on January 6, 2021. In the speech Trump said, among other things, that the election was stolen, that he and his supporter will never concede, that they will fight like hell, and that they are going to walk down to the Capitol because you'll never take your country back with weakness. $4^{4}$

Right after this speech a large mob of Trump supporters stormed the U.S. Capitol building, leading to the death of 5 people, the injury of at least 138 police officers, physical property damages in excess of 30 million dollars, the abrupt halt of an ongoing congressional

\footnotetext{
${ }^{4}$ See online appendix A for direct quotes from the speech.
} 
debate, and the immediate evacuation of all members of Congress whose lives were in severe danger.

I regard this event as a clear case of democratic backsliding that should be recognized and electorally sanctioned as such if the U.S. electorate is indeed to function as an effective check against overt undemocratic behavior by elected officials.

\section{Identification strategy}

To study whether the American electorate punishes overt undemocratic behavior by elected officials I exploit that the insurrection unexpectedly occurred while Gallup was conducting a nationally representative public opinion survey among 1,023 adult Americans using random digit dialing.5

Causal identification relies on two assumptions. First, temporal ignorability, meaning that whether any particular individual is interviewed before or after January 6 should be orthogonal to any other individual-level characteristic that also affects vote preferences. Second, excludability, meaning that the timing of interview should affect vote preferences only through the insurrection event, not through any other channel (Muñoz, Falcó-Gimeno and Hernández, 2020).

\subsection{Temporal ignorability}

Temporal ignorability is likely to hold for four reasons.

First, Gallup interviews over the phone and samples respondents using random digit dialing. This ensures that any individual, regardless of where he/she lives, and regardless of his/her own background characteristics, has an equal probability to be contacted for an

${ }^{5}$ As is shown in online appendix B the Gallup survey was conducted from January 4 until January 15, with 177 people having been interviewed before January 6 and 715 people having been interviewed after January 6 . 
Figure 1: Balance on observables.

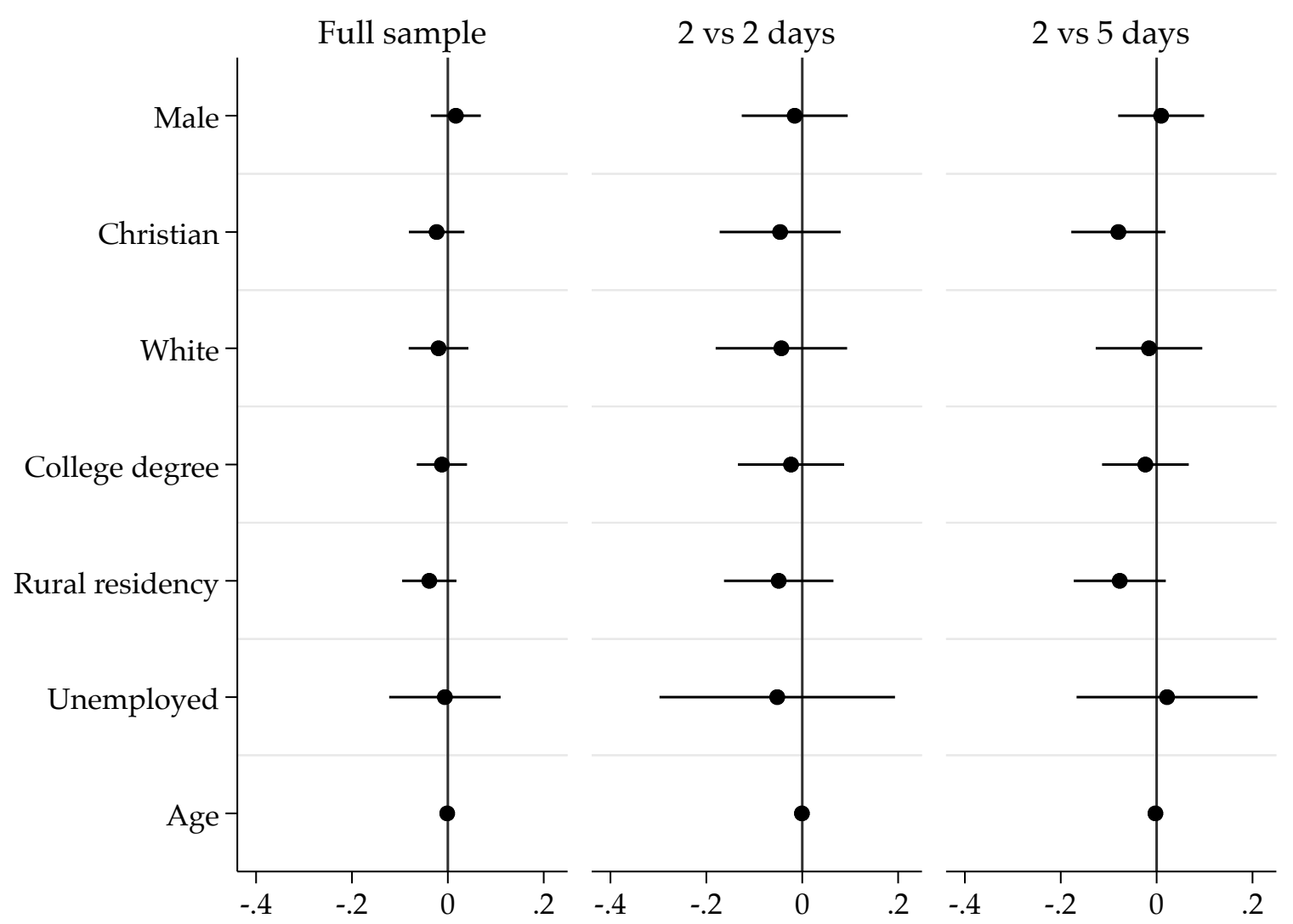

Note: Each dot represents an individual OLS regression. Dependent variable is treatment status. Point estimates and $95 \%$ confidence intervals are reported.

interview on any particular day. In line with this I find that the control and treatment groups are balanced on common pre-treatment determinants of Republican Party support (see figure 1) ${ }^{6}$

Second, there is no evidence of endogenous reachability differences (i.e., a priori Democrats being more difficult to reach for an interview and therefore being disproportionally included

${ }^{6} \mathrm{As}$ is standard in studies that use unexpectedly interrupted surveys for causal inference I drop the treatment day itself from the sample in all estimations. All results hold when assigning all the 118 respondents that were interviewed on January 6 to either the control or the treatment group. 
in the treatment group). First, the number of tries before an interview was successfully completed is uncorrelated with supporting the Republican Party (OLS coefficient: -0.022; P-value: 0.199). Second, all results hold when dropping all respondents that were not successfully interviewed on the first try (OLS coefficient: -0.141; P-value: 0.006).

Third, there is no indication of endogenous social desirability bias. If it were true that Republicans were disproportionally more likely to be interested in concealing their vote preference as a result of January 6, 2021 one would reasonably expect that: (1) non-responses on the vote preference question went up after January 6; and (2) support for Independents, rather than Democrats, went up after January 6 (i.e., assuming that selecting Independents would still be socially "acceptable" while preferable over Democrats for "Republicans in disguise"). This is not what the data suggests. Instead, there is no economically or statistically significant difference in non-response on the vote question before and after January 6 (OLS coefficient: 0.004; P-value: 0.661), and support tends to predominantly shift to the Democratic Party, rather than Independent, after January 6 (see table 1 below).

Last, there is no evidence that Republicans were altogether less likely to participate in the Gallup survey because of the January 6 insurrection 7 First, notice that passing the balance on observables test in figure 1 in the presence of endogenous survey non-response would require Republicans that disproportionally choose to opt out of the survey after January 6 to be similar to the voter profile of Democrats on average. Second, a placebo test using a dummy that takes the value 1 if a respondent is in favor of further restrictions on abortion, and 0 otherwise, suggests that the treatment group is, if anything, over representing a priori Republicans (OLS coefficient: 0.068; P-value: 0.190).

\subsection{Excludability}

Excludability is likely to hold for two reasons.

${ }^{7}$ Gallup unfortunately does not provide me with data on vote choice in the 2020 presidential election, which would have allowed me to test this assumption directly. 
First, a content analysis of the New York Times, the Wall Street Journal, and the USA Today suggests that there were no other events that occurred on or around January 6, 2021 that could plausibly explain a major shift in electoral support from the Republican Party towards the Democratic Party (see online appendix C).

Second, while it is true that the storming of the U.S. Capitol also exposed a major policy failure of the Washington, D.C. government to secure the Capitol building, which could have an independent effect on vote preferences, this collateral event weights against finding that January 6 led to a major electoral shift from the Republican Party towards the Democratic Party. This is because the government of Washington, D.C. was at the time of the insurrection fully controlled by Democrats.

\section{Results}

\subsection{Baseline Estimates}

In table 1 I use OLS to regress dummies that take the value 1 if a respondent supports or leans towards supporting Republican, Independent, or Democrat, and 0 otherwise, on a dummy that takes the value 1 if a respondent was surveyed after January 6, 2021, and 0 if he/she was surveyed before this date. $\left.\mathrm{Afl}^{0}\right|^{0}$

The estimate in panel A column (1) suggests that Donald Trump's incitement of the insurrection led to a $10.8 \%$ decline in electoral support for the Republican Party. This effect is statistically significant on the $99 \%$ confidence level. Panel A columns (3) and (5) suggest that $8.4 \%$ of this loss for the Republican Party shifted directly to the Democratic Party,

${ }^{8}$ I choose to use linear probability models for ease of interpretation. All results hold with logit/probit (see online appendix E).

${ }^{9}$ See online appendix D for descriptive (nonparametric) results.

${ }^{10}$ Note that I cannot observe effects on actual voting behavior because there was no ongoing election around January 6, 2021. Evidence from other settings nonetheless suggests that intended vote choices reported in surveys tend to closely correspond to real-world vote choices (Hainmueller, Hangartner and Yamamoto, 2015). 
Table 1: Effect January 6 insurrection on vote preference.

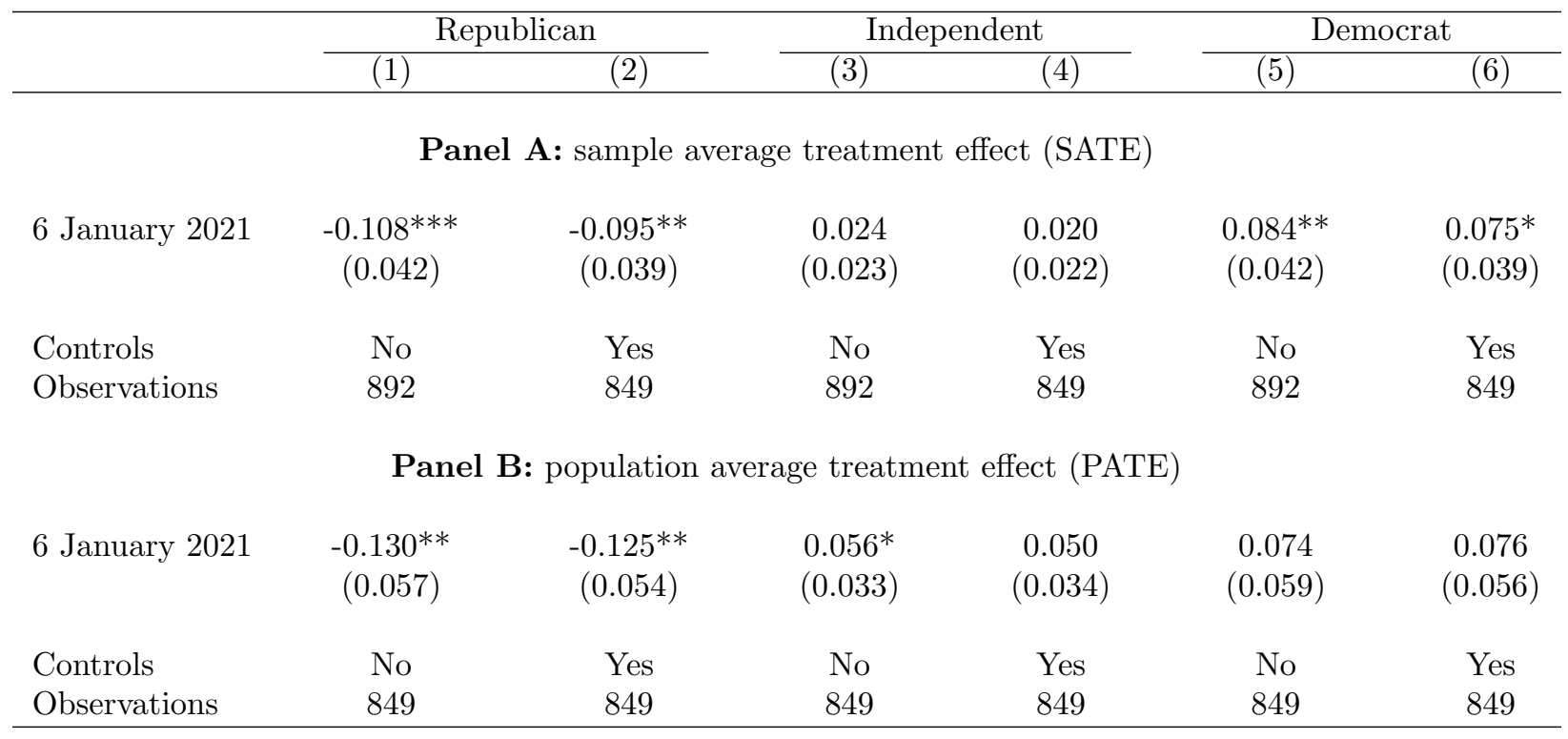

Notes: Each column within panel A and B is a separate OLS regression. Huber-White heteroscedasticityconsistent standard errors in parentheses.

$* * * \mathrm{p}<0.01, * * \mathrm{p}<0.05, * \mathrm{p}<0.10$.

while the remaining $2.4 \%$ came to reclassify themselves as Independents.

These results suggest that the Republican Party received a "double" electoral penalty as a result of Donald Trump's incitement of the insurrection: not only did the Republican Party heavily lost many of its own supporters, but most of its own supporters moved directly to the only other party that can reasonably win contemporary U.S. presidential elections. This also suggests that the effect is not driven by extremist Republican voters turning their back on the Republican Party because they felt that some other Republican leaders (e.g., Mitch McConnell) were not sufficiently supportive of Donald Trump after he incited the insurrection (i.e., assuming that such voters would not reclassify themselves as Democrats, rather than Independents, to give expression to this belief). Rather, the effect appears mostly driven by moderate Republicans willing to move across party lines as a response to the overt undemocratic behavior of a Republican president. 


\subsection{Robustness}

In panel $\mathrm{B}$ of table $1 \mathrm{I}$ examine whether these results hold when using American National Election Study data and probability weights to make the Gallup sample more closely resemble the American electorate in terms of age, gender, race, Christianity, education, rurality, and employment status (see online appendix $\mathrm{F}$ for more details). As can be seen using these probability weights, if anything, strengthens the results 11

Columns (2), (4), and (6) show that both the weighted and unweighted results remain essentially unchanged when controlling for the covariates from figure 1. All results also hold with geographical fixed effects for state, zipcode, or census region, and when controlling for: income, marital status, Muslim, Jewish, Atheist/Agnostic, 4-category Christian classification, self-identified intensity of religiosity, regularity of church attendance, 8-category education classification, Black, Hispanic, and Asian ethnicity/race.

In figure 2 I find that the estimated effect is highly stable when narrowing the sample to only include respondents that were surveyed directly before/after January 6, 2021. The point estimate in all cases hoovers around a $10 \%$ reduction in vote share for the Republican Party (note that the estimate is not statistically significant on the $95 \%$ level in the first two days because of a lack of statistical power, not because the treatment effect is substantively smaller).

In online appendix F I examine the effect on a dummy that takes the value 1 if a respondent approves of Donald Trump's job as president, and 0 otherwise. Using this alternative dependent variable I find, if anything, even stronger results (baseline OLS coefficient: -0.113; P-value: 0.007).

\footnotetext{
${ }^{11}$ As I generate the weights using ten distinct covariates in a sample of only 849 the weighting exercise somewhat increases the standard errors. The main effect nonetheless remains statistically significant on the $95 \%$ level.
} 
Figure 2: SATE and PATE estimates with less days after January 6 included in the sample.

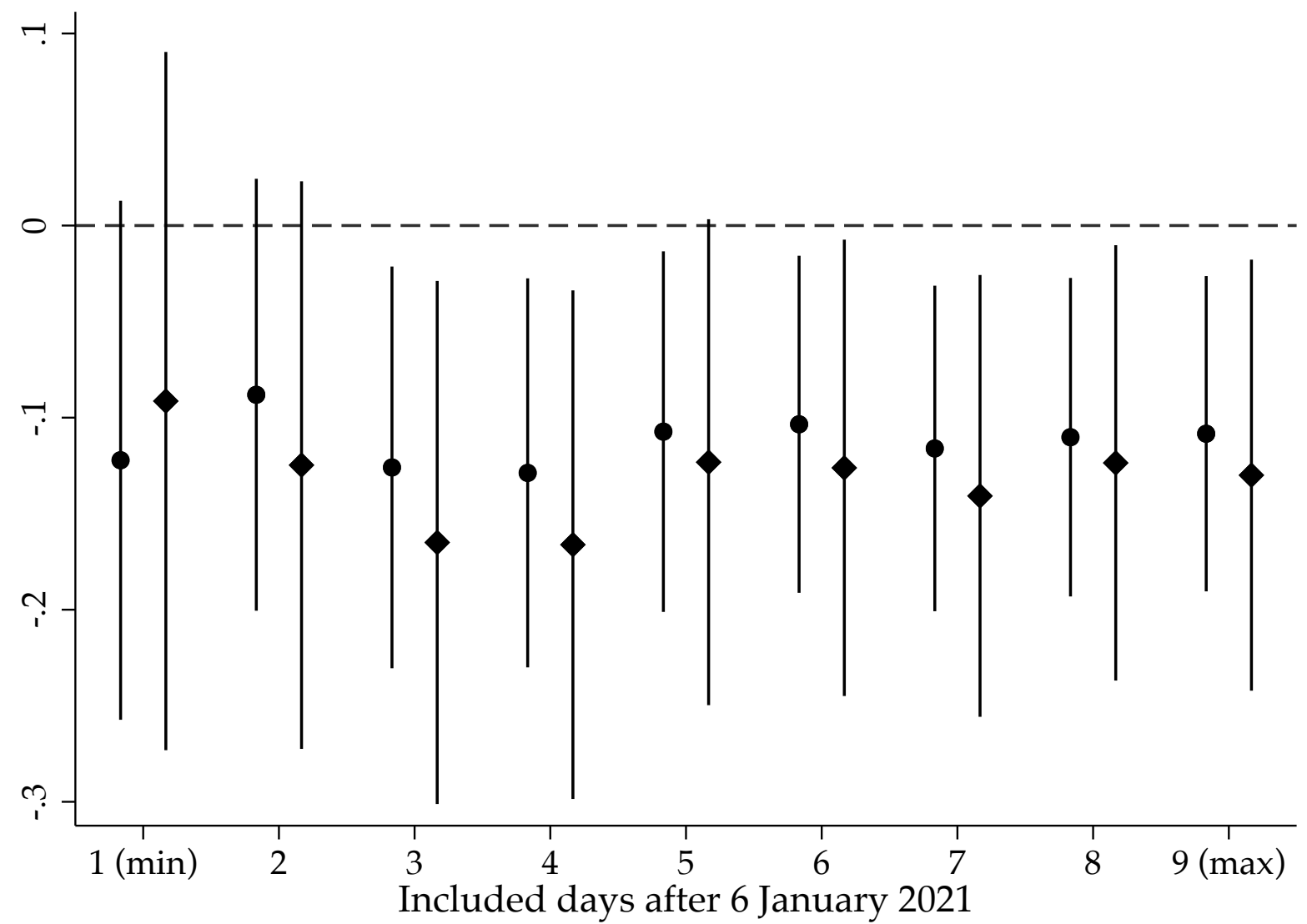

Note: Point estimates and 95\% confidence intervals of OLS regressions of supporting the Republican party on treatment status. The horizontal axis plots how many days after January 6, 2021 are included in the treatment group. The control group always consists of all respondents that were interviewed on January 4 and 5. Circles indicate SATE estimates. Diamonds indicate PATE estimates.

\subsection{Treatment Durability}

In terms of how long the effect lasted there is no sign that the treatment effect diminished within the sample itself. Limiting the sample to the post-January 6 period I find that the number of days a respondent is interviewed after January 6 is uncorrelated with support for the Republican Party (OLS coefficient: 0.002; P-value: 0.803).

Assessing how long the effect lasted outside of the sample is more challenging because including data from several weeks or even months after January 6 is likely to increase the probability that any observed differences in vote preferences are (also) driven by other 
Table 2: Party support relative to voter distribution on January 4 and 5, 2021.

\begin{tabular}{|c|c|c|c|c|}
\hline & 3-18 February & 1-15 March & 1-21 April & 3-18 May \\
\hline Republican & $-3.74 \%$ & $-5.27 \%$ & $-3.73 \%$ & $-4.05 \%$ \\
\hline Independent & $-0.49 \%$ & $+1.27 \%$ & $-1.51 \%$ & $-0.75 \%$ \\
\hline Democrat & $+4.24 \%$ & $+2.52 \%$ & $+3.27 \%$ & $+3.33 \%$ \\
\hline
\end{tabular}

Notes: Dates in column heading refer to fieldwork periods of Gallup "Mood of the Nation" surveys.

events/trends that happened after January 6, 2021.

Correlational evidence from table 2 nonetheless suggests that the effect reduces until about half its original size in a month but then remains stable from there. Even 4 months after January 6, 2021 average support for the Republican Party was still 4\% below, and Democratic Party support was still 3\% above, what it was in the days before the insurrection 12

\subsection{Treatment Heterogeneity}

As expected, the effect is stronger among urban (-0.110) relative to rural respondents (0.071), stronger among non-Christian (-0.120) relative to Christian respondents (-0.086), and stronger among employed (-0.111) relative to unemployed respondents (-0.069). Perhaps counterintuitively, the effect is stronger among males (-0.136) relative to females (0.084), stronger among whites (-0.132) relative to non-whites (-0.021), and stronger among non-college (-0.122) relative to college graduates (-0.096). These latter effects are driven by significantly lower support for the Republican Party pre-treatment. Relative to their lower pre-treatment mean non-whites, females, and college graduates actually made a larger respective electoral adjustment because of Donald Trump's incitement of the insurrection. In terms of geographical treatment heterogeneity I find the effect to be -0.102 versus -0.108 in states that did and did not vote Republican in the 2020 presidential election, and -0.092 versus -0.116 in the swing versus non-swings states of the 2020 presidential election.

\footnotetext{
${ }^{12}$ No more recent data is available at this point.
} 


\section{Conclusion}

This paper has shown that the American electorate does act as an effective electoral check on democratic backsliding, at least when the undemocratic behavior by a politician is as extreme as inciting an insurrection to overturn the result of a free and fair election. This is in contrast to much recent survey experimental evidence that has generally found that only a small fraction of Americans tends to prioritize democratic principles in their electoral choices, particularly in the current highly polarized climate.

While this is a hopeful message it is also very clear that the American electorate is very far from a perfect check on undemocratic behavior by elected officials. Indeed, if the American electorate was a perfect check on undemocratic behavior by politicians we would presumably see much less of the many instances of smaller, but nonetheless very serious, forms of democratic norm transgressions in America today (e.g., gerrymandering).

Further research is therefore necessary with regard to the important question of how extreme undemocratic behavior has to become before American voters react in sufficient severity. Future research is also necessary with regard to the important question of why the Republican Party has not reacted to Donald Trump's incitement of the January 6 insurrection by distancing itself from Donald Trump and the insurrectionists. Misjudgment, perhaps partly due to how the media has covered the insurrection and its aftermath, may play an important role here. Such types of information deficiencies are in the end widespread among Republican politicians (Broockman and Skovron, 2018). 


\section{References}

Albertus, Michael and Guy Grossman. 2021. "The Americas: When Do Voters Support Power Grabs?" Journal of Democracy 32(2):116-131.

Bermeo, Nancy. 2016. "On Democratic Backsliding." Journal of Democracy 27(1):5-19.

Broockman, David E. and Christopher Skovron. 2018. "Bias in Perceptions of Public Opinion among Political Elites." American Political Science Review 112(3):542-563.

Carey, John, Katherine Clayton, Gretchen Helmke, Brendan Nyhan, Mitchell Sanders and Susan Stokes. 2020. "Who Will Defend Democracy? Evaluating Tradeoffs in Candidate Support Among Partisan Donors and Voters." Journal of Elections, Public Opinion and Parties 0(0):1-16.

Cho, Young Ho and Injeong Hwang. 2021. "Who Defends Democracy and Why? Explaining the Participation in the 2016-2017 Candlelight Protest in South Korea." Democratization 28(3):625-644.

Cleary, Matthew R and Aykut Öztürk. 2020. "When Does Backsliding Lead to Breakdown? Uncertainty and Opposition Strategies in Democracies at Risk." Perspectives on Politics pp. $1-17$.

Graham, Matthew H. and Milan W. Svolik. 2020. "Democracy in America? Partisanship, Polarization, and the Robustness of Support for Democracy in the United States." American Political Science Review 114(2):392-409.

Grillo, Edoardo and Carlo Prato. Forthcoming. "Reference Points and Democratic Backsliding." American Journal of Political Science .

Haggard, Stephan and Robert Kaufman. 2021. "The Anatomy of Democratic Backsliding." Journal of Democracy 32(4):27-41.

Hainmueller, Jens, Dominik Hangartner and Teppei Yamamoto. 2015. "Validating Vignette and Conjoint Survey Experiments Against Real-World Behavior." Proceedings of the National Academy of Sciences 112(8):2395-2400.

Lührmann, Anna. 2021. "Disrupting the Autocratization Sequence: Towards Democratic 
Resilience." Democratization 28(5):1017-1039.

Magaloni, Beatriz. 2006. Voting for Autocracy: Hegemonic Party Survival and its Demise in Mexico. Vol. 296 Cambridge University Press.

McCoy, Jennifer, Gabor Simonovits and Levente Littvay. 2020. "Democratic Hypocrisy: Polarized Citizens Support Democracy-Eroding Behavior When Their Own Party is in Power." APSA Preprints.

Muñoz, Jordi, Albert Falcó-Gimeno and Enrique Hernández. 2020. "Unexpected Event during Survey Design: Promise and Pitfalls for Causal Inference." Political Analysis 28(2):186-206.

Svolik, Milan W. 2019. "Polarization versus Democracy." Journal of Democracy 30(3):20-32.

Svolik, Milan W. 2020. "When Polarization Trumps Civic Virtue: Partisan Conflict and the Subversion of Democracy by Incumbents." Quarterly Journal of Political Science 15(1):331.

Waldner, David and Ellen Lust. 2018. "Unwelcome Change: Coming to Terms with Democratic Backsliding." Annual Review of Political Science 21:93-113.

YouGov. 2021. "Most Voters Say the Events at the US Capitol Are a Threat to Democracy." January 6, 2021. 